\title{
Welcome to the second issue
}

We will continue to develop the structure of Journal to provide multi-disciplinary perspectives on cutting edge information. Our papers will continue to be published under a Creative Commons license and we will provide free access to all our issues. In this spirit, we have joined the Open Journal Systems developed by the Public Knowledge Project and now you can submit your papers directly through our website: www.basicandclinicalsciences.com after your registration as author.

The Basic and Clinical Sciences has Open Access policy that changes the way in which papers are published. First, all papers become freely and universally accessible online for readers and researchers, so an author's work can be read by anyone at no cost. Second, the authors hold copyright for their work and grant anyone the right to reproduce and disseminate the article, provided that it is correctly cited and no errors are introduced in its content. Third, a copy of the full text of each Open Access article is permanently archived in other online repositories separate from the journal.

The mission statement of the Journal is to publish articles that will help the professionals working in medicine and health sciences while they perform their responsibilities more effectively and efficiently for the increased benefit of their patients. The Journal aims to publish papers from around the world and read worldwide.

I wish the Editorial Board and the Journal continuing success in the coming years.

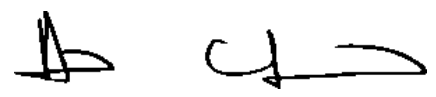

Prof. Ali Çetin, MD

Editor-in-Chief 